\title{
KLASIFIKASI PENENTUAN PENERIMA MANFAAT PROGRAM KELUARGA HARAPAN (PKH) MENGGUNAKAN ALGORITMA C5.0 (Studi kasus: Desa Sukamaju, Kec.Kadudampit)
}

\author{
1Dede Wintana, ${ }^{2}$ Hikmatulloh, ${ }^{3}$ Nurul Ichsan, ${ }^{4}$ Jajang Jaya Purnama,5Ami \\ Rahmawati. \\ 1,2,3,4,5 Universitas Bina Sarana Informatika, \\ 1,2,3,4,5Jl. Kamal Raya No.18, RT.6 / RW.3, Bar Cengkareng Kecamatan Cengkareng, \\ Kota Jakarta Barat, Daerah Khusus Ibukota Jakarta 11730. \\ ${ }^{1}$ Dede.dwe@bsi.ac.id, ${ }^{2}$ Hikmatul0808@bsi.ac.id, ${ }^{3}$ nurul.nrc@bsi.ac.id \\ 4jajangja2412@bsi.ac.id 5amirahma0304@bsi.ac.id,
}

\begin{abstract}
Poverty is the main focus of the central government and local governments. Because it is one of the causes of backwardness and an obstacle in the development of a nation. With the existence of a family program, it is expected that it can improve the socio-economic conditions of the Very Poor Family, increase the level of Very Poor Family education and improve the health and nutrition status of pregnant women and toddlers in Indonesia. Very Poor Family. The Family Hope Program is expected to reduce poverty and improve human resources, especially in the group of very poor people. The main problem in channeling the Hope Family Program was that the eligibility determination system was still manual and used data several years ago. This is feared to cause confusion and inaccuracy of beneficiaries of the Family Hope Program, so a decision support system is needed to determine the qualifications of recipients of the Hope Family Program. The results of the study using C5.0 Algorithm from this study, can know that the main root in determining recipients of family planning programs is the ownership of school children with acquisition of 0.512716784
\end{abstract}

Keywords: C5.0, Decision tree, Poverty, Classification, Hope family program.

\begin{abstract}
Abstrak
Kemiskinan adalah fokus utama pemerintah pusat dan pemerintah daerah. Karena itu merupakan salah satu faktor penyebab keterbelakangan dan penghambat dalam pembangunan suatu bangsa. Dengan adanya program keluarga, diharapkan diharapkan dapat meningkatkan kondisi sosial ekonomi Keluarga Sangat Miskin, meningkatkan tingkat pendidikan Keluarga Sangat Miskin dan meningkatkan status kesehatan dan gizi ibu hamil dan balita di Indonesia. Keluarga yang Sangat Miskin. Program Keluarga Harapan diharapkan dapat mengurangi kemiskinan dan meningkatkan sumber daya manusia, terutama pada kelompok orang yang sangat miskin. Masalah utama dalam menyalurkan Program Program Keluarga Harapan adalah bahwa sistem pemilihan penentuan kelayakan masih manual dan menggunakan data beberapa tahun yang lalu. Hal ini dikhawatirkan menyebabkan kebingungan dan ketidaktepatan penerima manfaat Program Keluarga Harapan, sehingga diperlukan sistem pendukung keputusan untuk menentukan kualifikasi penerima Program Keluarga Harapan. Hasil penelitian dengan menggunakan Algoritma C5.O
\end{abstract}


dari penelitian ini, dapat ketahui bahwa akar utama dalam menentukan penerima program keluarga harapan adalah kepemilikan anak sekolah dengan perolehan 0,512716784

Kata Kunci: C5.0, Decision tree, Kemiskinan, Klasifikasi, Program keluarga Harapan.

\section{PENDAHULUAN}

Kemiskinan menjadi salah satu fokus utama perhatian pemerintah pusat dan pemerintahan daerah. Salah satu faktor penyebab ketertinggalan dan penghambat dalam pembangunan suatu bangsa adalah tingginya angka kemiskinan. Masalah kemiskinan merupakan salah satu persoalan mendasar yang menjadi pusat perhatian pemerintah di negara manapun. [5] Indonesia merupakan salah satu negara berkembang yang sedang berjuang mengatasi masalah kemiskinan. Pada tahun 2017, persentase penduduk Indonesia yang hidup dalam kemiskinan tercatat sebesar $10.1 \%$. [10]

Program-program yang dilaksanakan dalam upaya pengentasan kemiskinan belum mampu memberikan dampak besar, sehingga tujuan dari pembanguanan nasional terkait masalah pemerataan kesejahteraan masyarakat masih menjadi masalah berkepanjangan.

Oleh karena itu pemerintah meluncurkan program Program Keluarga Harapan $(\mathrm{PKH})$ untuk menanggulangi masalah kemiskinan. (Utomo, Hakim, \& Ribawanto , 2018) Program Keluarga Harapan (PKH) dilatar belakangi oleh masih tingginya angka kemiskinan di berbagai daerah yang terdapat di Indonesia, Penanggulangan kemiskinan ini sebagai bentuk kebijakan pembangunan merupakan tanggung jawab seluruh elemen negara, meskipun dana dan keuangan yang disediakan oleh negara atau pemerintah jumlahnya terbatas.[8]

Keberadaan PKH bertujuan untuk meningkatkan kondisi sosial ekonomi KSM, meningkatkan taraf pendidikan anak-anak KSM serta meningkatkan status kesehatan dan gizi ibu hamil dan balita KSM. Pada akhirnya, PKH diharapkan tdak sekedar mampu menurunkan angka kemiskinan dan meningkatkan sumber daya manusia terutama pada kelompok masyarakat sangat miskin, tetapi dapat juga memutuskan rantai kemiskinan itu sendir[2]

Melalui wawancara ditemukan masalah mengenai penentuan penerima Bantuan Program Keluarga Harapan (PKH) pada Kantor Desa Sukamaju. Sistem seleksi penentuan kelayakan masih bersifat manual serta menggunakan data pada beberapa tahun yang lalu. Hal ini dikhawatirkan menimbulkan suatu kerancuan dan ketidak tepatan dalam menilai sehingga PKH tidak sampai kepada masyarakat kurang mampu yang benar-benar membutuhkan[3]

penelitian terdahulu yang cukup mendekati adalah penelitian yang dilakukan oleh sri anjarwati dan paradibah (2017) yang menggunakan agoritma Analytical Hierarchy Process (AHP) dan Preference Ranking Organization Methode for Enrichment Evaluation (Promethee). Kelebihan dari AHP adalah AHP memiliki banyak keunggulan dalam menjelaskan proses pengambilan keputusan. Salah satunya adalah dapat digambarkan secara grafis sehingga mudah dipahami oleh semua pihak yang terlibat dalam pengambilan keputusan. 
Penelitian lain yang juga menngunakan metode AHP yaitu penelitian yang dilakukan oleh Nur Aminudin dan Ida Ayu Puspita Sari yang berjudul Sistem pendukung keputusan (DSS) penerima bantuan program keluarga harapan (PKH) pada desa Sukamaju, Kec.Kadudampit, Kab.Sukabumi. dengan menggunakan metode Analytical Hierarcy Process (AHP) mengemukakan kelemahan dari Algoritma Analytical Hierarchy Process (AHP) yaitu Ketergantungan model ini terhadap input berupa persepsi seorang ahli akan membuat hasil akhir dari model ini menjadi tidak ada artinya apabila si ahli memberikan penilaian yang keliru.Kebanyakan orang bertanya apakah persepsi dari seorang ahli tersebut dapat mewakili kepentingan orang banyak atau tidak.

Berdasarkan masalah tersebut diperlukan sebuah sistem klasifikasi penerima program keluarga harapan (PKH) dengan menerpakan metode Algoritma C5.0

Algoritma C5.0 dianggap sebagai algoritma yang sangat membantu dalam melakukan klasifikasi data karena karakteristik data yang diklasifikasi dapat diperoleh dengan jelas baik dalam bentuk struktur pohon keputusan maupun aturan if then, sehingga memudahkan pengguna dalam melakukan penggalian informasi terhadap data yang bersangkutan [9]

Algoritma C5.0 merupakan algoritma berbasis decision tree yang merupakan penyempurnaan dari algoritma ID3 dan C4.5 yang dibentuk oleh Ross Quinlan pada tahun 1987. Algortima C5.0 dapat menangani atribut kontinyu dan diskrit. Pemilihan atribut dalam algoritma ini akan diproses menggunakan information gain, sehingga kesalahan yang ditimbulkan dalam pengambilan keputusan lebih diminimalkan [6]

Hasil pohon keputusan C5.0 dapat dipangkas atau terdapat pruning (pemangkasan). Atribut dengan nilai information gain tertinggi akan terpilih sebagai parent bagi node selanjutnya. Algoritma ini membentuk pohon keputusan dengan cara pembagian dan menguasai sampel secara rekursif dari atas ke bawah. Algoritma ini dimulai dengan semua data yang dijadikan akar dari pohon keputusan sedangkan atribut yang dipilih akan menjadi pembagi bagi sampel tersebut.

$$
\text { I } s 1, s 2, \ldots, s m=-\sum p i m i=1 \log 2 p i
$$

$\mathrm{S}$ adalah sebuah himpunan yang terdiri dari s data sampel. Diketahui atribut class adalah m dimana mendefinisikan kelas-kelas di dalamnya, Ci (for $\mathrm{i}=1, \ldots, \mathrm{m}$ ), si adalah jumlah sampel pada S dalam class Ci. untuk mengklasifikasikan sampel yang digunakan maka diperlukan informasi dengan menggunakan aturan 3. Dimana pi adalah proporsi kelas dalam output seperti pada kelas Ci dan diestimasikan dengan si /s. Atribut A memiliki nilai tertentu $\{a 1, a 2, \ldots$, av $\}$. Atribut A dapat digunakan pada partisi $S$ ke dalam v subset, $\{S 1, S 2, \ldots, S v\}$, dimana $S$ j berisi sample pada $S$ yang bernilai aj pada A. Jika A dipilih sebagai atribut tes (sebagai contoh atribut terbaik untuk split), maka subset ini akan berhubungan pada cabang dari node himpunan S. Sij adalah jumlah sample pada class Ci dalam sebuah subset Sj. Untuk mendapatkan informasi nilai subset dari atribut A tersebut maka digunakan formula,

$$
E A=\sum s 1 j+\ldots+s m j s I(s 1 j, \ldots, s m j) y j=1 s 1 j+\ldots+s m j s
$$


adalah jumlah subset $\mathrm{j}$ yang dibagi dengan jumlah sampel pada $\mathrm{S}$, maka untuk mendapatkan nilai gain, selanjutnya digunakan formula,

Gain $A=I s 1, s 2, \ldots, s m-E A$

Berdasarkan masalah diatas dapat di rumuskan permasalahan yang akan diselasaikan yaitu:

a. Bagaimana untuk menentukan pembagian bantuan PKH tersebut,

b. Bagaimana Menentukan system pendukung keputusan yang harus di ambil, Agar pembagian bantuan PKH di desa Sukamaju tepat sasaran untuk di berikan kepada masyarakat yang kurang mampu dan layak untuk mendapatkanya.

Pada penelitian ini batasan masalah dilakukan dengan agar sesuai dengan apa yang diharapkan hingga mencapai tujuan dapat tercapai. Adapun batasan masalah yang di bahas pada penelitian ini yaitu:

a. Agar pembagian bantuan PKH i, tepat sasaran untuk di berikan kepada masyarakat yang kurang mampu dan layak untuk menerimanya

b. Sampel data yang digunkan pada penelitian ini dari desa Sukamaju, Kec.Kadudampit, Kab.Sukabumi

c. Metode pengambilan data pada penelitian ini yaitu menggunakan Kuesioner.

Tujuan dari penelitian ini berguna untuk Menerapkan metode C5.0 dalam perencanaan system penunjang keputusan bagi masyarakat penerima bantuan, membangun suatu model pengambilan keputusan dengan mengunakan Algoritma C5.0 untuk menentukan siapa yang akan menerima Bantuan PKH sesuai dengan persyaratan yang di tentukan. Serta mencegah terjadinya kesalahan penerima bantuan Program Keluarga Harapan (PKH).

\section{METODE PENELITIAN}

Pada penelitian ini menggunakan data primer,dengan menggunakan teknik pengambilan data berdasarkan karakteristik demografi (besar dan struktur keluarga), karakteristik ekonomi (pekerjaan kepala keluarga dan istri, kepemilikan balita, Kepemilikan anak sekolah dan kontributor terhadap penerimaan keluarga, jenis dinding yang digunakan). Pengumpulan data dilakukan data primer dari desa data desa Sukamaju, dan pada penelitian menggunakan algoritma C5.0.

Algoritma C5.0 merupakan merupakan penyempurnaan dari algoritma terdahulu yang dibentuk oleh Ross Quinlan pada tahun 1987, yaitu algoritma ID3 dan C4.5. Dalam memilih atribut untuk pemecah objek dalam beberapa kelas harus dipilih atribut yang menghasilkan information gain paling besar. algoritma C5.0 menghasilkan tingkat keakuratan yang lebih tinggi dalam hal prediksi Penggunaan algoritma C5.0 dapat menghasilkan model prediksi dengan hasil tingkat akurasi yang lebih tinggi [1] algoritma C5.0 diharapkan proses penggalian informasi lebih 
cepat dan optimal dengan kapasitas data yang lebih besar, sehingga kesalahan yang ditimbulkan dalam pengambilan keputusan lebih diminimalkan[6]

Kelebihan algoritma C5.0 adalah Dapat menganalisis basis data subtansial yang berisi banyak record dan field numerik dan nominal. Data yang digunakan untuk tugas akhir ini adalah data studi akademik mahasiswa yang terdapat pada Igracias [1].Mampu mengakomodasi variabel yang bersifat continue dan variabel yang bersifat diskrit. Untuk variabel yang bersifat diskrit, akan diperlakukan nilai variabel tersebut sebagai splitter [9]

C5.0 menghasilkan tree dengan jumlah cabang per node bervariasi. C5.0 memperlakukan variabel kontinyu sama dengan yang dilakukan oleh CART, tetapi untuk variabel kategorikal C5.0 memperlakukan nilai variabel kategorikal sebagai Splitter

Strategi pengembangan decision tree dengan menggunakan alogritma C5.0 adalah sebagai berikut:

a. Pada tahap awal, tree digambarkan sebagai node tunggal yang merepresentasikan training set.

b. Jika sampel seluruhnya berisi kelas yang sama, maka node tersebut menjadi leaf dan dilabeli dengan kelas tersebut.

c. Jika tidak, algoritma dengan menggunakan ukuran berbasis entropi (information gain) akan memilih variabel prediktor yang akan memisahkan record ke dalam kelas-kelas individual. Variabel tersebut menjadi variabel tes atau keputusan pada node tersebut.

d. Cabang dikembangkan untuk tiap nilai yang diketahui dari variabel tes, dan sampel dipartisi berdasarkan cabang tersebut.

e. Algoritma menggunakan proses yang sama secara rekursif membentuk decision tree.

f. Partisi rekursif berakhir hanya ketika satu dari kondisi-kondisi berikut terpenuhi:

1) Seluruh record pada node tertentu memiliki kelas yang sama

2) Tidak ada atribut yang tersisa pada record yang dapat dipartisi lebih lanjut. Dalam kasus ini suara mayoritas digunakan. Node tersebut menjadi leaf node dan dilabeli dengan kelas yang menjadi mayoritas dalam record yang ada

3) Tidak ada record untuk cabang variabel tes. Dalam kasus ini, leaf terbentuk dengan mayoritas kelas sebagai label record tersebut 


\section{HASIL DAN PEMBASAN}

\subsection{Analisa Data Mining Untuk Klasifikasi Penerima Manfaat Program Keluarga Harapan}

Untuk mencapai tujuan akhir dari manfaat penelitian ini, telah dilakukan pengumpulan data dari desa Sukamaju, bertujuan untuk menentukan keputusan calon penerima program keluarga Harapan.

\subsection{Implementasi Algoritma C5.0}

Setelah data dimasukan dan dibagi perkelas maka dibuatlah sebuah pohon keputusan berdasarkan beberapa kelas sebagai berikut:

a. Jenis Dinding Rumah
1) Bambu
2) Tembok

b. Pekerjaaan
1) Pedagang
2) Buruhtani
3) Petani
4) PNS/TNI/Polri
5) Belum/tidak bekerja

c. Kepemilikan balita

1) Memiliki

2) Tidak Memiliki

d. Kepemilikin Anak Sekolah

1) Memiliki

2) Tidak Memiliki

Variabel Yang digunakan adalah LAYAK dan TIDAK LAYAK

\subsection{Pohon Keputusan}

Dalam pembuatan pohon keputusan maka dihitung jumlah kasus, Jumlah kasus keputusan yang layak dan jumlah kasus keputusan yang tidak layak berdasarkan jenis dinding rumah yang digunakan, pekerjaan yang dijalani, kepemilikan balita, dan kepemilikan anak yang masih sekolah. Selanjutnya menghitung jumlah gain setiap atribut.

Menentukan atribut sebagai akar dan menghitung nilai informasi gain atribut Untuk memilih atribut sebagai akar, didasarkan pada nilai gain tertinggi dari atribut-atribut yang ada. Dibutuhkan nilai Entropy untuk menentukan gain tertinggi. Menghitung Nilai Entropy tiap-tiap atribut Entropy (Total) dengan rumus sebagai berikut :

Entropy $(S)=(-259 / 418 \cdot \log 2(259 / 418)+(-159 / 418 \cdot \log 2(159 / 418))=\mathbf{0 , 9 5 8 3 1 1 9 1 6}$

Entropy (total) adalah menghitung nilai total keputusan Layak (259) dan Tidak layak (159), sedangkan 418 adalah jumlah keseluruhan kasus.

Setelah nilai entropy dan gain dihitung, kemudian hasil dari perhitungan tersebut dimasukkan ke dalam tabel berikut. 


\begin{tabular}{|c|c|c|c|c|c|c|c|}
\hline \multirow{3}{*}{ Node } & \multicolumn{7}{|c|}{ Gambar 3.1 Data Diolah (2018) } \\
\hline & \multirow[t]{2}{*}{ Atribut } & & $\begin{array}{c}\text { Jumlah } \\
\text { Kasus }\end{array}$ & LAYAK & TIDAK & \multirow[t]{2}{*}{ Entropy (I) } & \multirow[t]{2}{*}{$\operatorname{Gain}(\mathrm{G})$} \\
\hline & & & (S) & (S1) & (S2) & & \\
\hline & ENTROPY & & 410 & 254 & 156 & 0,958385815 & \\
\hline & TOTAL & & & & & & \\
\hline \multirow[t]{4}{*}{1} & JENIS DINDING & & & & & & 0,299395169 \\
\hline & RUMAH & & & & & & \\
\hline & & BAMBU & 136 & 136 & 0 & 0 & \\
\hline & & TEMBOK & 274 & 118 & 156 & 0,986080893 & \\
\hline \multirow[t]{6}{*}{2} & PEKERJAAN & & & & & & 0,462660518 \\
\hline & & PEDAGANG & 81 & 12 & 69 & 0,605186577 & \\
\hline & & BURUH TANI & 111 & 103 & 8 & 0,373609071 & \\
\hline & & PETANI & 114 & 64 & 50 & 0,98909344 & \\
\hline & & PNS/TNI/POLRI & 29 & 0 & 29 & 0 & \\
\hline & & $\begin{array}{l}\text { TIDAK/BELUM } \\
\text { BEKERJA }\end{array}$ & 75 & 75 & 0 & 0 & \\
\hline \multirow[t]{4}{*}{3} & MEMILIKI ANAK & & & & & & 0,499977307 \\
\hline & BALITA & & & & & & \\
\hline & & MEMILIKI & 209 & 205 & 4 & 0,136577216 & \\
\hline & & TIDAK & 201 & 48 & 153 & 0,793049005 & \\
\hline \multirow[t]{4}{*}{4} & MEMILIKI ANAK & & & & & & 0,512716784 \\
\hline & SEKOLAH & & & & & & \\
\hline & & MEMILIKI & 194 & 194 & 0 & 0 & \\
\hline & & TIDAK & 216 & 59 & 157 & 0,845945847 & \\
\hline
\end{tabular}

Pada Gambar 3.1 dapat diperoleh bahwa atribut kepemilikan anak memeiliki Gain paling tinggi yaitu $\mathbf{0 , 5 1 2 7 1 6 7 8 4}$ maka dapat dikatakan bahwa atribut kepemilikan anak dijadikan sebagai akar dari pohon keputusan yang akan kita buat.

Selanjutnya untuk penentuan Node 1.1 dilakukan sama dengan cara sebelumya yaitu menentukan nilai gain yang lebih tinggi dari atribut yang lainnya dan nilainya dibawah 0,512716784 atau lebih rendah dari atribut kepemilikan anak sekolah.

Gambar 3.2 Data diolah (2018)

\begin{tabular}{|c|c|c|c|c|c|c|}
\hline & & $\begin{array}{c}\text { Jumlah } \\
\text { Kasus }\end{array}$ & $\begin{array}{c}\text { LAYAK } \\
\text { (S1) }\end{array}$ & $\begin{array}{c}\text { TIDAK } \\
\text { (S2) }\end{array}$ & Entropy (I) & Gain (G) \\
\hline \multirow{4}{*}{$\begin{array}{l}\text { JENIS DINDING } \\
\text { RUMAH }\end{array}$} & & & & & & 0,126230576 \\
\hline & & & & & & \\
\hline & BAMBU & 14 & 14 & 0 & 0 & \\
\hline & TEMBOK & 206 & 47 & 159 & 0,774781761 & \\
\hline \multirow[t]{7}{*}{ PEKERJAAN } & & & & & & 0,282699719 \\
\hline & PEDAGANG & 80 & 9 & 71 & 0,507410964 & \\
\hline & PEKERJA LEPAS & 21 & 13 & 8 & 0,958711883 & \\
\hline & PETANI & 73 & 22 & 51 & 0,882958969 & \\
\hline & PNS/TNI/POLRI & 29 & 0 & 29 & 0 & \\
\hline & TIDAK/BELUM & 17 & 17 & 0 & 0 & \\
\hline & BEKERJA & & & & & \\
\hline
\end{tabular}


KEPEMILIKAN

BALITA

MEMILIKI

TIDAK
197

23

0,112622152

Pada gambar 3.2 diketahui bahwa atribut pekerjaan memiliki nilai tertinggi diantara atribut lainnya yaitu 0,282699719 dengan nilai tersebut atribut pekerjaan layak menjadi akar selanjutnya setelah atribut kepemilikan anak sekolah.

Selanjunya kita hitung node selanjutnya yaitu node 1.3 yang menggunakan metode dan cara sama seperti sebelumnya, hasil dari penghitungan tersebut adalah sebagai berkut:

Gambar 3.3 data diolah (2018)

\begin{tabular}{lcccccc}
\hline & & $\begin{array}{c}\text { Jumlah } \\
\text { Kasus }\end{array}$ & LAYAK & TIDAK & Entropy (I) & Gain (G) \\
\cline { 3 - 5 } & & (S) & (S1) & (S2) & & \\
\hline JENIS DINDING & & & & & & 0,048715255 \\
RUMAH & BAMBU & 2 & 2 & 0 & 0 & \\
& TEMBOK & 71 & 20 & 51 & 0,857743537 & \\
KEPEMILIKAN & & & & & & $\mathbf{0 , 6 9 9 1 9 7 0 4 9}$ \\
BALITA & MEMILIKI & 26 & 3 & 23 & 0,51594693 & \\
& TIDAK & 6 & 6 & 0 & 0 &
\end{tabular}

Dari gambar 3.3 tersebut dapat diketahu bahwa atribut atau akar selanjunya yang menentukan penerimaan program keluarga harapan adalah Kepemilikan balita yaitu 0,699197049 dengan hasil tersebut dapat diketahui juga atribut terakhir yang menjadi keputusan dalam menentukan kelayakan penerima program Keluarga Harapan didesa Sukamaju, Kadudampit,Sukabumi adalah Atribut Jenis dinding Rumah dengan nilai gain sebesar 0,048715255. Dari hasil tersebut dapat dikatahui pohon keputusan yang akan dibuat adalah sebagai berikut: 


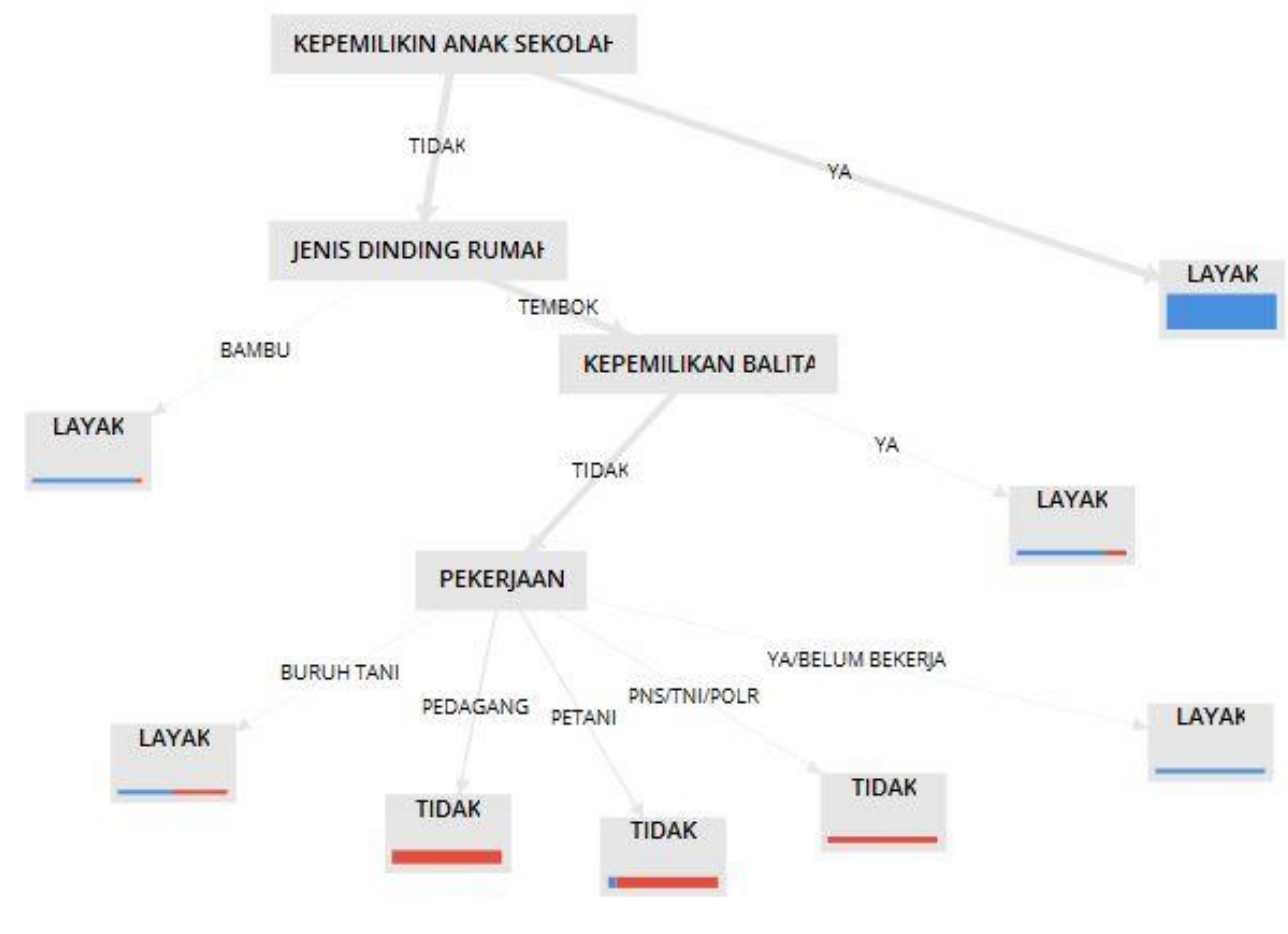

Gambar 3.4 Pohon Keputusan

Dari gambar pohon keputusan di atas dapat disimpulkan bahwa kepemilikan anak sekolah menjadi akar utama dalam penetuan penerima manfaat program keluarga harapan diikuti variabel jenis dinding rumah, selanjunya kepemilikan balitan dan yang terakhir adalah jenis pekerjaan.

\section{SIMPULAN}

Berdasarkan pembahasan yang telah dilakukan dengan teknik data mining dengan menggunakan algoritma C5.0 maka peneliti ini menarik beberapa kesimpulan yang penting. Adapun kesimpulan-kesimpulan tersebut adalah sebagai berikut:

a. Algoritma C5.0 dapat digunakan sebagai metode klasifikasi dalam penunjang keputusan penerima manfaat program keluarga harapan dengan memperhatikan nilai gain (penguatan) tertinggi dari empat atribut yaitu kepemilikan anak sekolah, jenis dinding rumah, kepemilikan balita, dan jenis pekerjaan yang biasa dilakukan.

b. Pohon Keputusan yang dihasilkan oleh teknik klasifikasi Algoritma C5.0 dari variabel yang memiliki gain tertinggi yaitu memiliki anak sekolah dapat menjadikan acuan dalampenentuan penerima manfaat program keluarga harapan dimasa yang akan datang.

c. Pohon keputusan yang dihasilkan bisa dijadikan bahan acuan atau bahan penelitian tentang klasifikasi penerima manfaat program keluarga harapan dengan cakupan yang lebih luas bukan hanya satu desa, bisa satu kecamatan, 
satu kota/kabupaten, bahkan cakupan yang lebih luas lagi supaya lebih generalisasi.

Saran dalam penelitian ini adalah dibuatnya software aplikasi pendukung keputusan kedepannya, bisa dibuatkan aplikasi berdasarkan penelitian ini baik menggunakan aplikasi Android, IOS, ataupun berbasis web.

\section{DAFTAR PUSTAKA}

[1]. Algoritma, C., Kasus, S., Ponsel, V., \& Hutabarat, C. (2018). PENERAPAN DATA MINING UNTUK MEMPREDIKSI PERMINTAAN PRODUK KARTU PERDANA INTERNET MENGGUNAKAN, 17(April), 168-173.

[2]. Aminudin, N., Ayu, I., \& Sari, P. (2015). Sistem Pendukung Keputusan (Dss) Penerima Bantuaprogram Keluarga Harapan (Pkh) Pada Desa Bangun Rejo Kec.Punduh Pidada Pesawaran Dengan Menggunakan Metode Analytical Hierarcy Process (Ahp). Jurnal TAM ( Technology Acceptance Model ), 5(2), 6672.

[3]. Anjarwati, S., \& Farahdibah. (2017). Penerima Bantuan Program Keluarga Harapan ( Pkh ) Dengan Metode Ahp Dan Promethee ( Studi Kasus Pada Kelurahan Kudaile Slawi ). Surya Informatika, 4(1), 1-14.

[4]. Haryanto, T., \& Nhita, F. (2013). Prediksi penyakin demam berdarah dan typhus dengan algoritma c5.0.

[5]. Kurniawan, I., \& Saputra, R. A. (2017). Penerapan Algoritma C5 . 0 Pada Sistem Pendukung Keputusan Kelayakan Penerimaan Beras Masyarakat Miskin. Jurnal Informatika, 4(2), 236-240.

[6]. Manik, R., \& Tampubolon, K. (2018). Prediksi Kolektibilitas Kredit Anggota Dengan Algoritma C5 . 0 ( Studi Kasus : CU Damai Sejahtera Medan ). Jurnal Riset Komputer (JURIKOM), 5(2), 151-160.

[7]. Munawaroh, H., Khusnul, B., \& Kustiyahningsih, Y. (2013). Perbandingan Algoritma ID3 dan C5.0 dalam Indentifikasi Penjurusan Siswa SMA. Jurnal Sarjana Teknik Informatika, 1(1), 1-12.

[8]. Purwanto, S. A., \& Makmur, M. (2013). IMPLEMENTASI KEBIJAKAN PROGRAM KELUARGA HARAPAN ( PKH ) DALAM MEMUTUS RANTAI KEMISKINAN ( Kajian di Kecamatan Mojosari Kabupaten Mojokerto ) The Policy Implementation of Prosperous Family Program ( $\mathrm{PKH}$ ) in Giving Social Protection to The Poor Community (, 16(2).

[9]. Susetyo, Y. A. (2018). Kombinasi Algoritma Spatial Autocorrelation G* dan Algoritma C5 . 0 untuk Deteksi Daerah Rawan Longsor di Pulau Jawa, 101-114.

[10]. Wijayaningrum, V. N. (2017). Optimasi Aturan Fuzzy Menggunakan Particle Swarm Optimization untuk Penentuan Prioritas Rumah Tangga Miskin, 10(01), 
$1-6$. 